\title{
Effect of indoor air quality of day care centers in children with different predisposition for asthma
}

\author{
Pedro Carreiro-Martins ${ }^{1,2,3}$, Ana Luisa Papoila ${ }^{3,4}$, lolanda Caires ${ }^{1}$, Susana Azevedo ${ }^{5}$, \\ Maria Manuela Cano ${ }^{6}$, Daniel Virella ${ }^{3}$, Paula Leiria-Pinto ${ }^{1,2}$, João Paulo Teixeira ${ }^{7,8}$, \\ José Rosado-Pinto ${ }^{9}$, Isabella Annesi-Maesano ${ }^{10}$ \& Nuno Neuparth ${ }^{1,2}$
}

${ }^{1}$ CEDOC, Respiratory Research Group, Nova Medical School, Campo dos Mártires da Pátria, Lisbon, Portugal; ${ }^{2}$ Serviço de Imunoalergologia, Hospital de Dona Estefânia, Centro Hospitalar de Lisboa Central, EPE, Lisbon, Portugal; ${ }^{3}$ Epidemiology and Statistics Analisys Unit, Research Centre, Centro Hospitalar de Lisboa Central, EPE, Lisbon, Portugal; ${ }^{4}$ CEAUL, Department of Biostatistic and Informatics, Nova Medical School, Campo dos Mártires da Pátria, 130, 1169-056, Lisbon, Portugal; ${ }^{5}$ National Laboratory for Civil Engineering, Lisbon, Portugal; ${ }^{6}$ Environmental Health Department, National Health Institute Doutor Ricardo Jorge - Lisboa, Lisbon, Portugal; ${ }^{7}$ Environmental Health Department, National Health Institute Doutor Ricardo Jorge - Porto, Oporto, Portugal; ${ }^{8}$ Institute of Public Health (ISPUP), University of Porto, Oporto, Portugal;

${ }^{9}$ Hospital da Luz, Lisbon, Portugal; ${ }^{10}$ Sorbonne Universités, UPMC Univ Paris 06, INSERM, Institut Pierre Louis d'Epidémiologie et de Santé Publique (IPLESP UMRS 1136), Epidemiology of Allergic and Respiratory diseases department (EPAR), Medical School Saint-Antoine, F75012 Paris, France

To cite this article: Carreiro-Martins P, Papoila AL, Caires I, Azevedo S, Cano MM, Virella D, Leiria-Pinto P, Teixeira JP, Rosado-Pinto J, Annesi-Maesano I, Neuparth N. Effect of indoor air quality of day care centers in children with different predisposition for asthma. Pediatr Allergy Immunol 2016: 27: 299-306.

\section{Keywords}

asthma; asthma predictive index; day care center; indoor air quality; volatile organic compounds; wheezing

\section{Correspondence}

Pedro Carreiro-Martins, CEDOC, Respiratory Research Group, Nova Medical School, Campo dos Mártires da Pátria, No. 130, 1169-056 Lisbon, Portugal

Tel.: +351218 803101

Fax: +351218 803010

E-mail: pmartinsalergo@gmail.com

Accepted for publication 6 December 2015

DOI:10.1111/pai.12521

\begin{abstract}
Background: Scarce information is available about the relationships between indoor air quality (IAQ) at day care centers (DCC), the estimated predisposition for asthma, and the actual wheezing susceptibility.

Methods: In the Phase II of ENVIRH study, 19 DCC were recruited after cluster analysis. Children were evaluated firstly using the ISAAC questionnaire and later by a follow-up questionnaire about recent wheezing. A positive asthma predictive index (API) was considered as predisposition for asthma. Every DCC was audited for IAQ and monitored for chemical and biologic contaminants.

Results: We included 1191 children, with a median age of $43\left(\mathrm{P}_{25}-\mathrm{P}_{75}\right.$ : 25-58) months. Considering the overall sample, in the first questionnaire, associations were found between $\mathrm{CO}_{2}$ concentration (increments of $200 \mathrm{ppm}$ ) and diagnosis of asthma (OR: 1.10 ; $95 \%$ CI: $1.00-1.20)$. Each increment of $100 \mu \mathrm{g} / \mathrm{m}^{3}$ of total volatile organic compounds (TVOC) and $1 \mu \mathrm{g}$ of Der $\mathrm{p} 1 / \mathrm{g}$ of dust were associated with wheezing in the previous 12 months (OR: 1.06; 95\% CI: 1.01-1.11 and OR: 1.06; 95\% CI: 0.99-1.12, respectively). In the follow-up questionnaire, TVOC were again associated with wheezing (OR: 1.05; 95\% CI: 1.00-1.11). Children exposed to fungal concentration above the 75th percentile had also higher odds of wheezing at follow-up. TVOC were associated with wheezing in children with either negative or positive API.

Conclusions: IAQ in DCC seems to be associated with wheezing, in children with and without predisposition for asthma.
\end{abstract}

Wheezing is very common in early childhood, and it has been associated with numerous factors, such as atopy, parental history of allergic respiratory disease, exposure to tobacco smoke, air pollutants, and allergen exposure $(1,2)$.

Some studies suggested the need to improve indoor air quality (IAQ) and ventilation at day care centers (DCC) $(3,4)$, as the early age stages of life are crucial for the development of allergies (5) and both chemical and biologic contaminants may trigger respiratory and allergic diseases. Young children spend most of their time indoors (6), at home, at school, or in DCC. The reported association between attending a DCC and respiratory symptoms, allergy, and infections (7) might be related to IAQ. Children are particularly vulnerable to environmental exposures $(5,8)$ because of their immunologic 
immaturity, incomplete lung development, and a higher exposure dose of inhaled agents due to their metabolic and ventilation rates (9).

The type of ventilation and the indoor carbon dioxide $\left(\mathrm{CO}_{2}\right)$ concentrations in DCC seem to be related to respiratory symptoms in children $(4,10)$. A low air renewal may elicit symptoms due to higher concentrations of chemical contaminants (3), such as particulate matter and volatile organic compounds. On the other hand, it might also suggest the presence of a more prone environment to spread respiratory infections. Moreover, biologic contaminants such as bacteria, fungi, and house dust mite could also be associated with respiratory illnesses (11) and promote the spreading of respiratory infections.

In spite of the evidence that atopic school-aged children exposed to air pollutants have increased risk of asthma in the previous year (12), it is still not clear whether the association between wheezing and the IAQ at DCC may differ according to the allergic background. Moreover, wheezing in infants and pre-school children is a heterogeneous condition with different phenotypes, and only a part will experience continued wheezing symptoms in later childhood and thus have the diagnosis of asthma (13).

This study reports results from the Phase II of ENVIRH study (Environment and Health in children day care centers), conducted in Portugal. It aimed to evaluate the association between wheezing and IAQ at DCC, and the variation of wheezing susceptibility to IAQ according to the estimated predisposition for asthma.

\section{Materials and methods}

\section{Study design, setting, and participants}

The ENVIRH project took place in the cities of Lisbon and Oporto (Portugal). It comprised two phases (14). Results from Phase I were already reported (10).

For Phase II, a cluster analysis of the 45 DCC included in Phase I (considering indoor $\mathrm{CO}_{2}$ concentrations, temperature, and humidity) was performed to select 19 DCC from the more different clusters (10 from Lisbon and nine from Oporto). Those DCC were attended by 2287 children. Children were evaluated firstly using the ISAAC questionnaire (April 2011) and later by a follow-up questionnaire about recent wheezing (May 2011). Every child attending the selected DCC was eligible for the study and was invited to participate. A detailed IAQ assessment was also conducted in Phase II (March to April 2011). The study flowchart is presented in the Fig. S1.

The ENVIRH project was approved by the Ethics Committee of Nova Medical School.

\section{Data sources for health assessment}

The first questionnaire was the Portuguese version of the ISAAC questionnaire (15). It was distributed to the parents of all children attending the selected DCC, coincidently with the IAQ assessment. For follow-up, a short health questionnaire focused on the occurrence of wheezing in the previous 2 months (March and April 2011) was distributed. Both questionnaires were handed out by the DCC staff and filled in by the parents.

\section{Indoor air quality measurements}

Assessment of indoor air quality was conducted in every room of the selected DCC. The study was carried out under typical occupation conditions, during daily activities and comprised the monitoring of chemical $\left(\mathrm{PM}_{10}\right.$, carbon dioxide, total volatile organic compounds - TVOC, and formaldehyde) and biologic (bacteria, fungi, and house dust mite - Der p1 allergen) contaminants, as well as thermal comfort parameters (indoor air temperature and relative humidity).

A more detailed description of the IAQ assessments was previously reported $(14,16)$. Additional information could be found as Supporting information.

\section{Variables}

The clinical outcomes of interest from the ISAAC questionnaire were wheezing in the previous 12 months, reported asthma diagnosis, wheezing during or after exercise, and cough at night. For the follow-up questionnaire, the clinical outcome was reported wheezing (at least one episode) in the previous 2 months.

The IAQ exposures were $\mathrm{PM}_{10}, \mathrm{CO}_{2}$, TVOC, house dust mite, total bacteria, and fungi.

Children with wheezing were considered as predisposed to asthma whether their asthma predictive index (API) was positive (13) and were classified in three groups according to the API major criteria (physician-diagnosed eczema or parental asthma) and minor criteria (physician diagnosis of allergic rhinitis and wheezing without colds). As no blood samples were drawn, minor criteria did not include eosinophilia. The groups were as follows: wheezing children with a positive stringent index (frequent early wheezer and one of the major or two of the minor criteria) (13), wheezing children with a positive loose index (early wheezer and one of the major or two of the minor criteria) (13), and wheezing children with a negative API (none of the previous criteria).

\section{Statistical analysis}

As children were nested in rooms and rooms were nested in DCC, to evaluate the association between clinical outcomes and chemical ( $\mathrm{PM}_{10}, \mathrm{CO}_{2}$, and TVOC) and biologic contaminants (house dust mite, total bacteria, and fungi), and comfort parameters (indoor air temperature and relative humidity), mixed-effects models that considered the structure of dependence between measurements were used, namely three-level logistic random-intercept model.

Crude odds ratios (OR) were calculated for the overall sample. For the multivariable analysis, a purposeful selection was carried out, after performing a univariable analysis. In this analysis, those variables having a $\mathrm{p}$-value $<0.25$ were selected as candidates for the multivariable analysis (17). 
Separate regression analyses were also conducted according to the wheezing pattern. In this sense, OR were calculated for children with a negative API, children with a positive loose index, and children with a positive stringent index. Crude and adjusted OR are reported with corresponding 95\% confidence intervals $(\mathrm{CI})$.

OR were calculated for each increment of $1 \mathrm{mg} / \mathrm{m}^{3}$ of $\mathrm{PM}_{10}$, for each increment of $200 \mathrm{ppm}$ of $\mathrm{CO}_{2}$, and for each increment of $100 \mu \mathrm{g} / \mathrm{m}^{3}$ of TVOC. House dust mite OR consider increments of $1 \mu \mathrm{g}$ of Der $\mathrm{pl} / \mathrm{g}$ of dust. Total bacteria and fungi were both dichotomized by their 75 th percentile.

A level of significance $\alpha=0.05$ was used, although p-values $>0.05$ and $<0.1$ were still considered as indicating an evidence, although weak, of an association between the indoor air contaminants and the respiratory outcomes. Given the exploratory nature of this study, no multiple testing corrections were performed. Data analysis was performed using stata (Stata Statistical Software: Release 12; StataCorp LP, Lakeway, TX, USA).

\section{Results}

\section{Characteristics of the children and the DCC}

A total of 125 classrooms were studied (73 in Lisbon and 52 in Oporto). The ISAAC questionnaire return rate was $52.3 \%$ $(\mathrm{n}=1221)$, although only 1191 valid questionnaires were considered for analysis. These 1191 children included 52.4\% boys and $47.6 \%$ girls, with a median age of 43 months $\left(\mathrm{P}_{25}\right.$ $\mathrm{P}_{75}$ : 25-58 months).

The description of the sample is presented in Table 1. In the first questionnaire, $48 \%$ of the children $(\mathrm{n}=571)$ presented a previous history of wheezing: $28 \%(\mathrm{n}=333)$, a negative API; $17 \%(n=202)$, a positive API loose index; and 3\% $(n=36)$, a positive API stringent index. The reported prevalences of wheezing and asthma in the previous 12 months were $28.8 \%$ (95\% CI: $26.3-31.5 \%$ ) and $4.5 \%$ (95\% CI: 3.5-5.9\%), respectively.

The chemical and biologic contaminants concentrations and the comfort parameters characteristics at the DCC are presented in Table 2.

\section{Associations between IAQ and wheezing-related conditions - overall sample}

Concerning the first questionnaire, the associations between IAQ and the reported clinical outcomes found in the univariable analysis for the overall sample (which included all the 571 children with a previous history of wheezing and the remaining 620 children without wheezing) are presented in Tables S2 and S3.

In the multivariable analysis, after adjusting for confounders (Tables 3 and 4), associations were found for the overall sample, between $\mathrm{CO}_{2}$ and asthma diagnosis (OR: 1.10; 95\% CI: $1.00-1.20, \mathrm{p}=0.041)$ and wheezing during or after exercise in the previous 12 months (OR: 1.12; 95\% CI: 1.04-1.21, $\mathrm{p}=0.002)$. TVOC were associated with wheezing in the previous 12 months (OR: 1.06; 95\% CI: 1.01-1.11,
Table 1 Children's sociodemographics characteristics and reported prevalence of wheezing-related conditions (prevalence and 95\% Cl)

First questionnaire $(n=1191)$

\begin{tabular}{|c|c|}
\hline \multicolumn{2}{|l|}{ City } \\
\hline Lisbon, \% & 59.9 \\
\hline Oporto, \% & 40.1 \\
\hline \multicolumn{2}{|l|}{ Gender } \\
\hline Male, \% (95\% Cl) & $52.4(49.5-55.2)$ \\
\hline Female, \% $(95 \% \mathrm{Cl})$ & $47.6(44.8-50.5)$ \\
\hline Age in months, median $\left(P_{25}-P_{75}\right)$ & $43(28-58)$ \\
\hline $\begin{array}{l}\text { Age in months at the time of the } \\
\text { enrollment in the } D C C \text {, } \\
\text { median }\left(P_{25}-P_{75}\right)\end{array}$ & $12(6-24)$ \\
\hline $\begin{array}{l}\text { DCC attendance time in months, } \\
\text { median }\left(P_{25}-P_{75}\right)\end{array}$ & $25(11-40)$ \\
\hline Maternal smoking, \% (95\% Cl) & $26.4(23.9-28.9)$ \\
\hline \multicolumn{2}{|l|}{ Parental education } \\
\hline Primary or secondary, \% (95\% Cl) & $67.6(64.9-70.2)$ \\
\hline High school or university, \% (95\% Cl) & $32.4(29.8-35.1)$ \\
\hline Existence of older siblings, $\%(95 \% \mathrm{Cl})$ & $47.0(44.2-49.9)$ \\
\hline Atopic dermatitis (eczema), \% (95\% Cl) & $13.9(12.1-16.0)$ \\
\hline $\begin{array}{l}\text { Parental history of asthma or } \\
\text { allergic rhinitis, \% }(95 \% \mathrm{Cl})\end{array}$ & $45.8(43.0-48.6)$ \\
\hline Dampness at home, \% (95\% Cl) & $33.8(31.2-36.6)$ \\
\hline Pets at home, \% $(95 \% \mathrm{Cl})$ & $22.3(20.1-24.8)$ \\
\hline Air conditioned at home, \% $(95 \% \mathrm{Cl})$ & $13.9(12.1-16.0)$ \\
\hline $\begin{array}{l}\text { Home surroundings - no green } \\
\text { areas, } \%(95 \% \mathrm{Cl})\end{array}$ & $39.9(37.1-42.7)$ \\
\hline Birthweight $<2500 \mathrm{~g}, \%(95 \% \mathrm{Cl})$ & $12.9(11.1-15.00)$ \\
\hline Preterm birth < 37 weeks, \% (95\% Cl) & $8.2(6.8-9.9)$ \\
\hline \multicolumn{2}{|l|}{ Wheezing and API classification } \\
\hline Never, \% $(95 \% \mathrm{Cl})$ & $52.0(49.2-54.8)$ \\
\hline $\begin{array}{l}\text { Previous history of wheezing } \\
\text { and a negative API, \% }(95 \% \mathrm{Cl})\end{array}$ & $28.0(25.5-30.6)$ \\
\hline $\begin{array}{l}\text { Children with a positive loose index, } \\
\%(95 \% \mathrm{Cl})\end{array}$ & $17.0(14.9-19.2)$ \\
\hline $\begin{array}{l}\text { Children with a positive stringent index, } \\
\%(95 \% \text { Cl })\end{array}$ & $3(2.2-4.2)$ \\
\hline $\begin{array}{l}\text { Wheezing in the previous } 12 \text { months, } \\
\%(95 \% \mathrm{Cl})\end{array}$ & $28.8(26.3-31.5)$ \\
\hline Asthma diagnosis, \% $(95 \% \mathrm{Cl})$ & $4.5(3.5-5.9)$ \\
\hline $\begin{array}{l}\text { Wheezing during or after the exercise in the } \\
\text { previous } 12 \text { months, } \%(95 \% \mathrm{Cl})\end{array}$ & $5.6(4.5-7.1)$ \\
\hline $\begin{array}{l}\text { Cough at night in the previous } 12 \text { months, } \\
\%(95 \% \mathrm{Cl})\end{array}$ & $34.3(31.6-37.0)$ \\
\hline
\end{tabular}

Follow-up $(n=637)$

Wheezing, \% (95\% Cl)

$25.4(22.2-29.0)$

$\mathrm{API}$, asthma predictive index; $\mathrm{Cl}$, confidence interval; $\mathrm{DCC}$, day care center; $P_{25}$, 25th percentile; $P_{75}$, 75th percentile.

$\mathrm{p}=0.011)$ and weakly associated with wheezing during or after exercise in the previous 12 months (OR: 1.03; 95\% CI: $1.00-1.07, \mathrm{p}=0.066)$. A weak association was also found for Der p1 allergen concentration and wheezing in the previous 
Table 2 Chemical and biologic contaminants concentration and comfort parameters characteristics at the DCC ( $n=125$ classrooms). Results are expressed as median $\left(\mathrm{P}_{25}-\mathrm{P}_{75}\right)$

\begin{tabular}{|c|c|}
\hline \multicolumn{2}{|l|}{ Indoor } \\
\hline \multicolumn{2}{|l|}{ Chemical contaminants } \\
\hline $\mathrm{PM}_{10}\left(\mu \mathrm{g} / \mathrm{m}^{3}\right)$ & $130(90-150)$ \\
\hline $\mathrm{CO}_{2}(\mathrm{ppm})$ & $1210(770-1536)$ \\
\hline TVOCs $\left(\mu \mathrm{g} / \mathrm{m}^{3}\right)$ & $140(70-180)$ \\
\hline Formaldehyde $\left(\mu \mathrm{g} / \mathrm{m}^{3}\right)$ & * \\
\hline \multicolumn{2}{|l|}{ Biologic contaminants } \\
\hline House dust mite - Der $\mathrm{p} 1$ ( $\mu \mathrm{g} / \mathrm{g}$ dust) & $0.67(0.46-0.83)$ \\
\hline Total bacteria $\left(\mathrm{CFU} / \mathrm{m}^{3}\right)$ & $3390(1960-8040)$ \\
\hline Fungi $\left(\mathrm{CFU} / \mathrm{m}^{3}\right)$ & $410(250-610)$ \\
\hline \multicolumn{2}{|l|}{ Comfort parameters } \\
\hline Temperature indoors $\left({ }^{\circ} \mathrm{C}\right)$ & $19.9(18.8-22.2)$ \\
\hline Relative Humidity indoors (\%) & $60(48.8-71.3)$ \\
\hline \multicolumn{2}{|l|}{ Outdoor } \\
\hline \multicolumn{2}{|l|}{ Chemical contaminants } \\
\hline $\mathrm{PM}_{10}\left(\mu \mathrm{g} / \mathrm{m}^{3}\right)$ & $270(240-550)$ \\
\hline $\mathrm{CO}_{2}(\mathrm{ppm})$ & $484(439-486)$ \\
\hline TVOCs $\left(\mu \mathrm{g} / \mathrm{m}^{3}\right)$ & $39(33-551)$ \\
\hline \multicolumn{2}{|l|}{ Biologic contaminants } \\
\hline Total bacteria (CFU) & $344(320-935)$ \\
\hline Fungi (CFU) & 780 (780-934) \\
\hline
\end{tabular}

DCC, day care center; CFU, Colony-forming units.

*Levels $\leq$ the detection limit $\left(20 \mu \mathrm{g} / \mathrm{m}^{3}\right)$ in $89 \%$ of the samples.

12 months (OR: 1.06; 95\% CI: 0.99-1.12, p = 0.077). Children exposed above the 75 th percentile of fungi concentration presented higher odds of cough at night in the previous 12 months (OR: 1.30; 95\% CI: 0.96-1.75, p = 0.091).

At the follow-up questionnaire, TVOC were associated with wheezing in the previous 2 months (OR: 1.05 ; 95\% CI: 1.00 $1.11, p=0.075)$. Children exposed above the 75 th percentile of fungi concentration presented also higher odds for wheezing.

\section{Associations between IAQ and wheezing-related conditions in children with a previous history of wheezing and a negative API}

Considering children with a previous history of wheezing and a negative API, in the multivariable analysis, TVOC associated with wheezing in the last 12 months (OR: 1.06; 95\% CI: 1.00 $1.12, \mathrm{p}=0.039)$. A weak association was also found between TVOC and wheezing during or after exercise (OR: 1.04; 95\% CI: $1.00-1.09, \mathrm{p}=0.081) . \mathrm{CO}_{2}$ associated with cough at night in the previous 12 months (OR: 1.05 ; 95\% CI: 1.00-1.11, $\mathrm{p}=0.056)$.

\section{Associations between IAQ and wheezing-related conditions in children with a positive API loose index}

In the multivariable analysis that considered wheezing children with a positive API loose index, TVOC concentration was strongly associated with wheezing in the previous 12 months (OR: 1.09 ; 95\% CI: $1.03-1.15, \mathrm{p}=0.002$ ). A tendency was found for $\mathrm{CO}_{2}$ to be associated with cough at night in the previous 12 months (OR: 1.13; 95\% CI: 0.98-1.29, $\mathrm{p}=0.092$ ). House dust mite were associated with wheezing during or after exercise (OR: 1.12; 95\% CI: 1.01-1.26, p = 0.034). High levels of fungi were also associated with cough at night in the previous 12 months (OR: 1.79; 95\% CI: 1.21-2.63, $\mathrm{p}=0.003$ ) and reported wheezing at the follow-up questionnaire (OR: 1.90 ; $95 \%$ CI: $1.03-3.45, \mathrm{p}=0.039$ ).

Associations between IAQ and wheezing-related conditions children with a positive API stringent index

The analysis of this group was hampered by the small number of children with positive API stringent index. In the univariable analysis, results were significant for the association between $\mathrm{CO}_{2}$ and wheezing during or after exercise. In the multivariable analysis, a tendency was found for TVOC to be associated with wheezing during or after exercise (OR: 1.20 ; 95\% CI: 0.99 $1.46, \mathrm{p}=0.062$ ).

\section{Combined effect of two contaminants on wheezing - overall sample}

The combined effect of the contaminants (TVOC and house dust mite) that showed a more relevant association with wheezing in the previous 12 months was tested in the whole sample. Results showed that these two contaminants were associated with that respiratory outcome after adjusting for other covariates and also considering an interaction term $(\mathrm{p}=0.060)$ between contaminants (TVOC - OR: $1.11 ; 95 \%$ CI: $1.04-1.17, \mathrm{p}=0.001$ and house dust mite - OR: $1.15 ; 95 \%$ CI: $1.02-1.30, \mathrm{p}=0.022$ ).

\section{Discussion}

In this study, we aimed to study the association of both chemical and biologic contaminants at DCC on wheezingrelated conditions and assess whether there were different susceptibilities to IAQ according to the predisposition for asthma. This predisposition was established on the basis of API, an index that has been useful to predict asthma in young children (18). For this purpose, we used a wellvalidated instrument that comprises questions that have been widely used as operational definitions of current asthma (19) or wheezing, including in children attending $\operatorname{DCC}(7)$.

TVOC and $\mathrm{CO}_{2}$ were the chemical contaminants that stand out in our results. In the overall sample, TVOC were associated with reported wheezing in both questionnaire assessments. Exposure to volatile organic compounds may constitute a significant health risk, even at low concentrations (20). In DCC, TVOC levels may result from the use of glues and paintings, during typical children activities. Young children may be more susceptible to TVOCs as a result of their higher susceptibility (5). Exposure to volatile organic compounds is related to different health adverse effects, as immunologic, respiratory, and carcinogenic. The mechanisms are not well understood but seem to include gene expression changes and activation of oxidative stress pathways (21). 


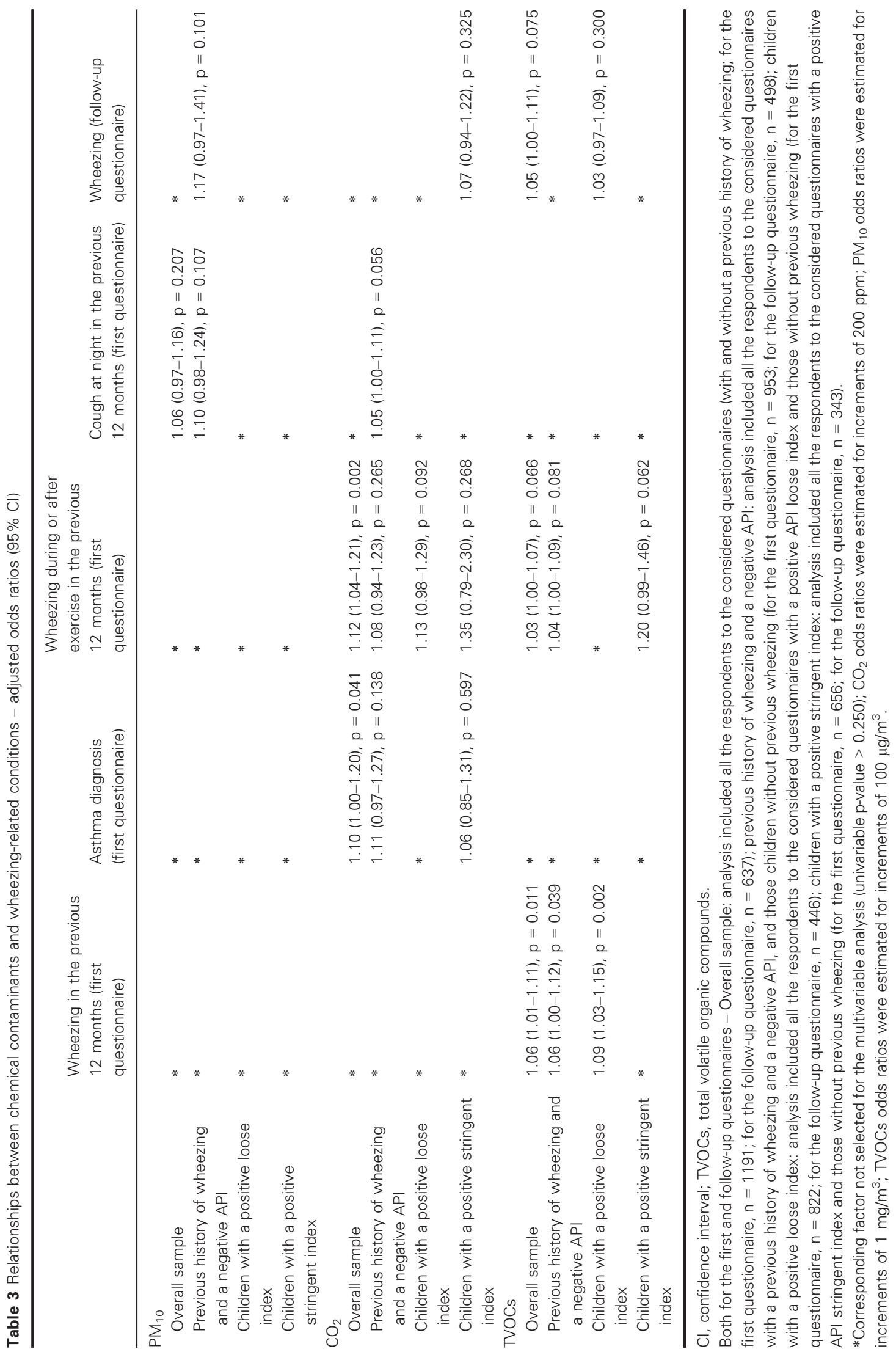




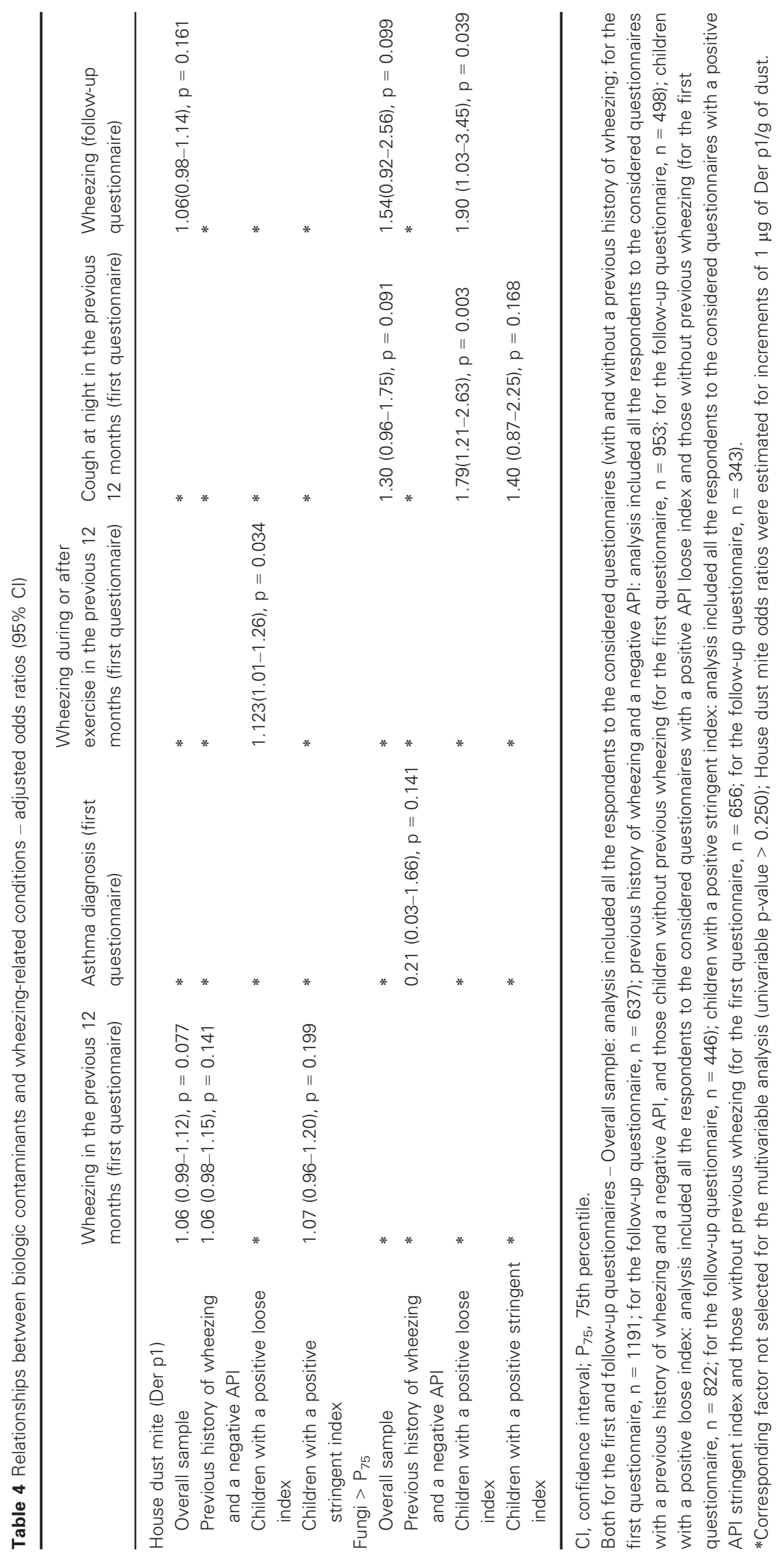


In the overall sample, $\mathrm{CO}_{2}$ concentration was related to asthma diagnosis and to wheezing during or after exercise in the previous 12 months. Associations with $\mathrm{CO}_{2}$ are in line with previous findings and suggest a need to improve ventilation $(10,22)$.

Concerning Der p 1 allergen, concentrations are in accordance with most of the results reported in the literature for schools and day care facilities (23). Moreover, the study of the combined effects of house dust mite and TVOCs indicated the presence of an interaction between these two contaminants, as previously described (24) for young children.

In our survey, fungi concentrations were related to wheezing and associations were stronger for children with asthma predisposition. Dampness in buildings is considered a risk factor for health effects in pre-school children (25), among atopics and non-atopics. The underlying mechanisms for the observed health effects are unclear and may include the inhalation of spores, fungal fragments, mycotoxins, and volatile organic compounds.

The high values of $\mathrm{PM}_{10}$ concentration found in the DCC were probably a consequence of children's activities that induce particulate matter resuspension $(26,27)$.

We found high concentrations of airborne bacteria above the recommended limit $\left(500 \mathrm{CFU} / \mathrm{m}^{3}\right)$ in most part of the DCC rooms. Sources of indoor airborne bacteria seem to be human oral and respiratory fluid emitted via coughing, sneezing, talking, breathing, and skin shedding (28).

Wheezing is a common symptom in early childhood and might be enhanced by DCC attendance (7). It could result from a combination of different factors, and for this reason, we considered in the analysis variables that have been related with wheezing in the literature.

The major strengths of this study are the inclusion of a carefully selected sample of DCC, the detailed characterization of each DCC concerning the IAQ, the health respiratory assessment, and the statistical analysis approach that took into consideration the correlation structure between the observations in each classroom and DCC. To our knowledge, this is the first study addressing the role of chemical and biologic contaminants in such settings, considering the predisposition for asthma.

We did not perform IAQ assessments in the children's homes, and this could constitute an uncontrolled bias of the study. However, the analysis took into consideration important dwelling environmental factors gathered through the ISAAC questionnaire.

The modest return rate of the handed questionnaires could be a consequence of the required active parental consent (29) and may have precluded estimating correct prevalences of the conditions. However, the obtained estimates are in line with previous results about wheezing and asthma prevalence in Portuguese young children (30). Nevertheless, we emphasize that the objective of this study was not to estimate prevalence but to explore the relationship between IAQ at DCC and wheezing in the attending children; therefore, these findings are plausible and should be understood as part of an exploratory study.

\section{Conclusion}

The results indicate an association between chemical and biologic contaminants at DCC and wheezing in young children. Those exposures seem to be relevant for every wheezing child, independently of the asthma predisposition.

\section{Acknowledgments}

The authors express their gratitude to the participant children, their parents, and caregivers for their essential contribution. The authors thank the DCC staff and the authorities involved in the study for their collaboration. The authors acknowledge the grant from Fundação para a Ciência e Tecnologia - ENVIRH Project PTDC/SAU-ESA/100275/2008 and PEst-OE/MAT/ UI0006/2014.

\section{References}

1. Subbarao P, Mandhane PJ, Sears MR. Asthma: epidemiology, etiology and risk factors. CMAJ 2009: 181: E181-90.

2. Porsbjerg C, von Linstow ML, Ulrik CS, Nepper-Christensen S, Backer V. Risk factors for onset of asthma: a 12-year prospective follow-up study. Chest 2006 : 129: 309-16.

3. St-Jean M, St-Amand A, Gilbert NL, et al. Indoor air quality in Montreal area day-care centres, Canada. Environ Res 2012: 118: 1-7.

4. Zuraimi MS, Tham KW, Chew FT, Ooi PL. The effect of ventilation strategies of child care centers on indoor air quality and respiratory health of children in Singapore. Indoor Air 2007: 17: 317-27.

5. Sly PD, Flack F. Susceptibility of children to environmental pollutants. Ann N Y Acad Sci 2008: 1140: 163-83.

6. Holt PG, Macaubas C, Stumbles PA, Sly PD. The role of allergy in the development of asthma. Nature 1999: 402(6760 Suppl.): B12-7.

7. Hagerhed-Engman L, Bornehag CG, Sundell J, Aberg N. Day-care attendance and increased risk for respiratory and allergic symptoms in preschool age. Allergy 2006: 61: 447-53.

8. Schwartz J. Air pollution and children's health. Pediatrics 2004: 113(4 Suppl.): 1037-43.

9. Moya J, Bearer CF, Etzel RA. Children's behavior and physiology and how it affects exposure to environmental contaminants. Pediatrics 2004: 113(4 Suppl.): 996-1006.

10. Carreiro-Martins P, Viegas J, Papoila AL, et al. $\mathrm{CO}_{2}$ concentration in day care centres is related to wheezing in attending children. Eur J Pediatr 2014: 173: 1041-9.

11. WHO Regional Office for Europe. WHO Guidelines for Indoor Air Quality: Dampness and Mould. Copenhagen: WHO Regional Office for Europe, 2009.
12. Annesi-Maesano I, Hulin M, Lavaud F, et al. Poor air quality in classrooms related to asthma and rhinitis in primary schoolchildren of the French 6 Cities Study. Thorax 2012: 67: 682-8.

13. Castro-Rodriguez JA, Holberg CJ, Wright AL, Martinez FD. A clinical index to define risk of asthma in young children with recurrent wheezing. Am J Respir Crit Care Med 2000: 162(4 Pt 1): 1403-6.

14. Araujo-Martins J, Carreiro Martins P, Viegas J, et al. Environment and health in children day care centres (ENVIRH) - study rationale and protocol. Rev Port Pneumol 2014: 20: 311-23.

15. Rosado-Pinto J. ISAAC (International Study of Asthma and Allergies in Childhood) - 20 anos em Portugal. Acta Pediatr Port 2011: 42: S25-47.

16. Mendes A, Aelenei D, Papoila AL, et al. Environmental and ventilation assessment in child day care centers in Porto: the 
ENVIRH project. $J$ Toxicol Environ Health A 2014: 77: 931-43.

17. Bursac Z, Gauss CH, Williams DK, Hosmer DW. Purposeful selection of variables in logistic regression. Source Code Biol Med 2008: 3: 17.

18. Castro-Rodriguez JA. The Asthma Predictive Index: a very useful tool for predicting asthma in young children. $J$ Allergy Clin Immunol 2010: 126: 212-6.

19. Sa-Sousa A, Jacinto T, Azevedo LF, et al. Operational definitions of asthma in recent epidemiological studies are inconsistent. Clin Transl Allergy 2014: 4: 24.

20. Viegi G, Simoni M, Scognamiglio A, et al. Indoor air pollution and airway disease. Int J Tuberc Lung Dis 2004: 8: 1401-15.

21. Buthbumrung N, Mahidol C, Navasumrit $\mathrm{P}$, et al. Oxidative DNA damage and influence of genetic polymorphisms among urban and rural schoolchildren exposed to benzene. Chem Biol Interact 2008: 172: 185-94.
22. Simoni M, Annesi-Maesano I, Sigsgaard T, et al. School air quality related to dry cough, rhinitis and nasal patency in children. Eur Respir J 2010: 35: 742-9.

23. Salo PM, Sever ML, Zeldin DC. Indoor allergens in school and day care environments. J Allergy Clin Immunol 2009: 124: 185-92, 92 e1-9; quiz 93-4.

24. Rumchev K, Spickett J, Bulsara M, Phillips M, Stick S. Association of domestic exposure to volatile organic compounds with asthma in young children. Thorax 2004: 59: 746-51.

25. Bornehag CG, Sundell J, Bonini S, et al. Dampness in buildings as a risk factor for health effects, EUROEXPO: a multidisciplinary review of the literature (1998-2000) on dampness and mite exposure in buildings and health effects. Indoor Air 2004: 14: 243-57.

26. Zhang G, Spickett J, Rumchev K, Lee AH, Stick S. Indoor environmental quality in a 'low allergen' school and three standard primary schools in Western Australia. Indoor Air 2006: 16: 74-80.

27. Janssen NA, Hoek G, Brunekreef B, Harssema H. Mass concentration and elemental composition of PM10 in classrooms. Occup Environ Med 1999: 56: 482-7.

28. Hospodsky D, Qian J, Nazaroff WW, et al. Human occupancy as a source of indoor airborne bacteria. PLOS ONE 2012: 7: e34867.

29. Ellwood P, Asher MI, Stewart AW. The impact of the method of consent on response rates in the ISAAC time trends study. Int $J$ Tuberc Lung Dis 2010: 14: 1059-65.

30. Morais-Almeida M, Santos N, Pereira AM, et al. Prevalence and classification of rhinitis in preschool children in Portugal: a nationwide study. Allergy 2013: 68: 1278-88.

\section{Supporting Information}

Additional Supporting Information may be found in the online version of this article:

Figure S1. Study flow chart (DCC: day care center; IAQ, Indoor air quality). Table S1. Relationships between children's characteristics and DCC comfort parameters and wheezing related conditions - crudes odds ratios $(95 \% \mathrm{CI})$
Table S2. Relationships between chemical contaminants and wheezingrelated conditions - crude odds ratios $(95 \% \mathrm{CI})$.

Table S3. Relationships between biologic contaminants and wheezingrelated conditions - crude odds ratios $(95 \% \mathrm{CI})$.

Data S1. Material and methods 